\title{
9
}

\section{FROM UNCERTAINTY TO CONTROLLABILITY, LEARNING AND INNOVATION}

\author{
Jan Holmström and Karri Kosonen \\ Department of Industrial Management, Helsinki University of Technology \\ Otakaari 1, 02150 Espoo, Finland
}

\begin{abstract}
To take the step from uncertainty to controllability and learning the industrial firm needs to recognize that both operational problems and problems of conflicting interests within the firm may be caused by its own planning and control procedures.

Capacity and delivery problems in the manufacturing industry are commonly a result of poor communication between members of the supply chain and of the chain members' internal practices to deal with variety. Pull control cannot always be applied to the extent necessary to solve the problem of distorted information. Thus, it is essential to recognize and accommodate the problems of distorted communication in the design of planning and control procedures. Based on a number of case studies from the Finnish manufacturing industry it is demonstrated that clarity and process overview are the cornerstones to reduce self induced control problems.
\end{abstract}

It is also argued that down-stream process transparency is not sufficient to achieve fast and fluent operations. To secure the cooperation of all actors in the value adding chain it is necessary to directly expose upstream operations to the final customer. A cultural benchmarking of employee attitudes and behavior in the Finnish metal working industry and the banking industry reveals the importance of direct customer exposure as a determinant of employee commitment.

Key words: operations development, self-induced operational uncertainty, customer exposure

\section{INTRODUCTION}

The difficulty of dealing formally with operational uncertainty is a primary reason for why operations management is necessary. However, uncertainty of the operational situation is often self-induced and amplified by bad communication in a changing environment. Simply put, it is possible for an industrial firm to acquire enough relevant knowledge about its operational situation to avoid much uncertainty and reduce the need for direct management control and decision making.

Senge (1990) very succinctly defines the complexity caused by the delay between action and outcome as dynamic complexity and observes that this type of complexity is extremely difficult to deal with or even acknowledge. However, ignoring the effects of slow communication has, as will be demonstrated in this paper, dire consequences on the firms ability to be competitive.

From the study of supply chains it has been demonstrated that small demand fluctuations are amplified to upstream operations (Houlihan, 1987; Towill, 1992). 
This phenomenon was first described by Forrester (1958). In a supply chain a small and controllable ripple of the end customer demand is easily distorted to a substantial and strongly cyclical pattern of surging and falling demand for upstream companies. Because the time interval between demand surges may be several years the problem is easily associated with changes in the economic environment.

For a company far removed from the consumer it is very costly and difficult to deal with uncertainty of demand and to provide customers with reliable service. Unreliable delivery performance is the direct consequence of upstream companies having too little capacity to deal with unexpected demand surges. The response of down stream companies is to hold buffer inventory against unreliable supply. However, since communication of end customer demand is distorted by attempts to control buffer inventories, the companies of the supply chain are caught in a positive feed back trap where the efforts to deal with uncertain demand and delivery only increases the uncertainty of the situation.

There is, besides the length of the supply chain, another equally important source of demand distortion, which is variety. Product variety in combination with inflexible capacity encourages firms to extend response times in order to achieve some degree of scale benefits, which in turn results in demand distortion very similar to that of a long supply chain. Product variety is also a key disabling factor for improved profitability of industrial firms. Analysis of the extensive PIMS database indicates that customized products are the single most significant factor in explaining poor profitability in manufacturing industries (Buzzel \& Gale, 1987). Both increased operational cycles and small batch production has a negative effect on efficiency, and thus also profitability.

\section{REDUCING SELF-INDUCED OPERATIONAL UNCERTAINTY}

The issue of variety implies that distortion of demand is not purely a problem of interfirm communication. The internal organization of many companies is not designed to master the dynamic complexity of an uncertain environment. The controllability of the value adding process is poor, i.e. the firm is not able to effectively pursue its market opportunities due to the constraints posed by long throughput times, inflexible capacity and inability to quickly procure the necessary materials. Buffers and attempts to achieve economies of scale slows down communication within the firm and misconstrues decision makers understanding of the value adding process.

When the perceptions of decision makers responsible for different aspects of the operation diverge the ability to adapt to changing circumstances weakens. Additionally, inadequate communication and control practices may create situations where it appears that the difficulties experienced are solely caused by the environment, even though substantial causes are to be found within the organization.

Burbidge (1989) observes that a major internal source of uncertainty are the load surges caused by multicycle control of production. Weekly loads fluctuate strongly in a manufacturing process where several different parts with different planning cycles are made. The solution to this self-inflicted problem of varying capacity requirements is to control the production of all parts within the same cycle. The quantity to be produced of each part varies from period to period. (see e.g. Burbidge 1994) 
Unsynchronized control practices induces uncertainty by distorting communication in the value chain. An example of this relationship between operational uncertainty, controllability and communication is evident in the case of a small Finnish electronics subcontractor. In this case unsynchronized material control practices was found to contribute to operational uncertainty. In the company the use of MRP (Material Resource Planning) severed the link between production planning and purchasing. The result was that the company experienced severe difficulties to respond reliably to changes in demand.

The initial situation in controlling materials and the new practices devised by management to improve controllability and reduce operational uncertainty will be used to illustrate the point (Figure 1.).

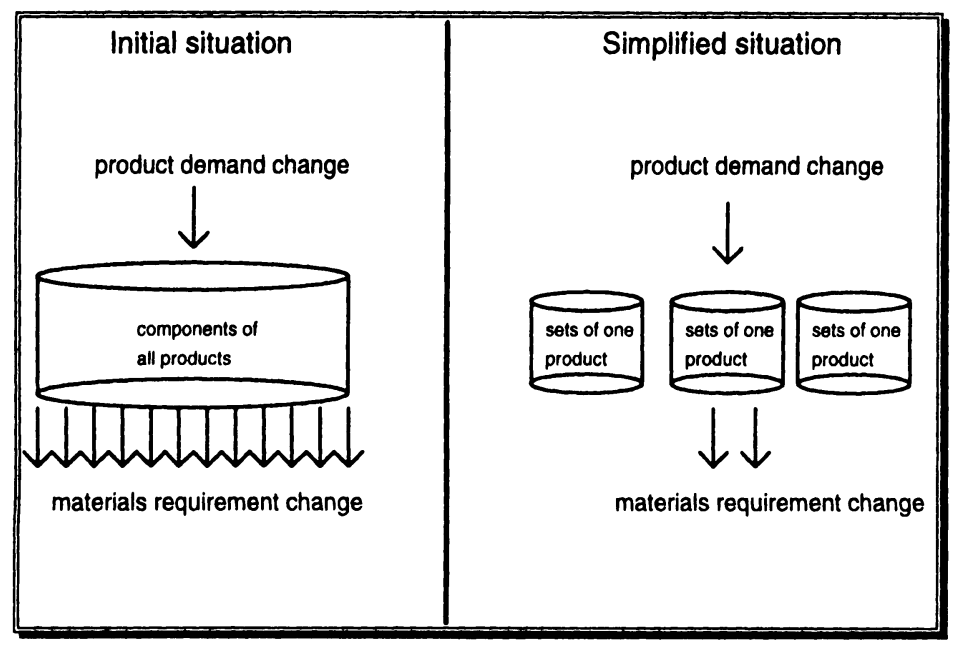

Figure 1: Improving controllability and reducing operational uncertainty through fast and accurate communication

Initially material requirements were controlled with a centralized information system. Components were controlled individually. This weakened the connection between product demand and materials requirements. A change in product demand caused an avalanche of purchase orders needing attention. Due to the number of materials in the individual products and the effort involved in adapting to changes it was difficult to keep up with whether enough materials were procured and whether unnecessary orders were canceled. This is a typical situation of self-induced operational uncertainty and low controllability.

The new practices devised simplifies the operational situation and improves communication by grouping materials in product specific sets. The communication of demand changes and their impact on materials requirements is direct and fast. There is little uncertainty of the operational situation and high controllability. This simplification also allows for reduced buffering, i.e. a speeding up of the operation. However, it must be pointed out, that to be effective the new practices requires that the firm is capable of defining sets and finding suppliers for the sets.

Controllability is the capability of the firm to pursue its goals, e.g. to seize market opportunities, reduce costs and improve profit, in a changing environment. The Just- 
in-Time model is commonly regarded as the simplest and clearest way to achieve high controllability and productivity in a manufacturing operation (see e.g. Schonberger, 1990 ). A Just-in-Time operation is demand driven with very little distortion of communication due to the direct feed back of pull control. Demand variations are equally visible in the whole value adding chain and the efficiency loss due to product variety is minimized by determined efforts to simplify material flows and reduce set up times.

The effect of introducing pull control in an operation that has previously been run in a batch production mode is dramatic. A Finnish supplier of engineered metal components for the electromechanical industry was able to cut throughput times and improve productivity by 50 per cent. This was the direct result of the elimination of waiting times and the material handling, production planning and control activities in batch production. A critical factor in the successful introduction of pull control was the ability and willingness of local suppliers to deliver Just-in-Time.

However, simplifying material flows and reducing set up times is often a difficult task. Very small production runs also make it difficult to achieve a consistent quality in many types of manufacturing processes. Long processing times in upstream value adding activities also complicate the situation. Therefore a certain degree of planning ahead, i.e. push control, is often necessary. The critical issue of planning is how to minimize internal sources of uncertainty while retaining an effective use of resources.

It must be emphasized that an effective plan is simple to understand and easy to monitor. If it is not possible to simplify planning and control by grouping a production process in independent parallel flows, then a fixed planning cycle should be considered for control of the sequential value adding stages. This simplifies the task of maintaining flow according to demand and coordinating dependent parallel activities.

The objective when defining which sequential activities should be controlled together is to have as few stages to control as possible and to group the activities in such a way that the total throughput time is as short as possible. This approach is practical especially when the process times of different activities vary greatly. Thus, by determining the planning cycle according to the most time consuming activity and grouping as many other activities as possible together, both simplicity of planning and fast throughput can be achieved.

The case of a Finnish clothing manufacturer illustrates the importance of simplicity and clarity of planning in a situation where pull control is not possible. The company produces a wide range of product varieties in an integrated process covering knitting, dyeing, printing, cutting and sewing. The process is currently loosely controlled in half a dozen overlapping process stages with varying control cycles. The consequence of this approach is an average throughput time of 10 to 11 weeks, and a prohibitively large number of dependent activities to consider and control. Production problems surface slowly and tend to accumulate in downstream operations at the end of each four week scheduling period. However, by reducing and separating the control stages and introducing a fixed relay schedule it is possible to project demand with minimal distortion throughout the process. The benefit of this is, besides a reduction of throughput time to three weeks, that production and sales can have a common understanding of delivery capabilities and that any problems in producing according to plan are visible within a week. 
Controllability is the capability of the firm to pursue its goals in a changing environment. The ideal is to have pull control and organize production according to parallel product flows by using, for example, group technology techniques (see Burbidge, 1989). However, this is not always feasible. In that case much attention must be paid to avoid the undesirable surge effects of complex multi cycle control schemes. To achieve controllability it is critical that planning and monitoring of the operations is both simple and clear.

\section{OverComing CUltural ObSTACLES TO IMPROVEMENT}

The spectacular competitive success of Japanese manufacturing industries is commonly ascribed to innovations in production and quality management. It has also been claimed that the introduction of these practices have been more successful in Japan than in the West due to cultural differences. This is a reasonable, but false, explanation. Differences in successful implementation can be explained by the fact that the practices address specific obstacles to improvement in many Japanese organizations. Implementation and adaptation is also more straightforward with a clear understanding of purpose.

Practices that address specific obstacles to improvement which are common in a large number of situations can be expected to have a dramatic impact. The impact of the quality control movement in Japan illustrates the effect of overcoming an obstacle to improvement that is rooted in the norms and values of management and employees. The respect for authority and seniority was identified as a very common inhibiting factor to tackle problems of bad quality in the Japanese industry (Ishikawa, 1985). Until the late 1940's quality efforts were guided by the perceptions of senior employees and not on the basis of analysis and facts. Even when a person performing the task knew the problem it was not possible for him to bring it to the surface so that something could be done about it. The "Quality-Story" format of problem solving with its emphasis on quantitative evidence was eventually adopted to overcome this cultural barrier to improvement (Lillrank, 1988; Ishikawa, 1985).

Leverage to achieve outstanding quality was found by breaking up the existing norms and values that prevented effective actions to improve quality. This development transformed the traditional work organization, where production work was divided into simple independent tasks and where planning and control responsibility was in the hands of specialists and supervisors. The emphasis on quality improvement and the introduction of statistical quality control techniques on the shop floor transferred control and problem solving responsibility from specialist functions to the value adding activities themselves (Drucker, 1990). In the wake of successful quality improvement, JIT production control could also be effectively introduced.

The Japanese quality movement illustrates an important point of successful operations development: There are specific actions that can have a pivotal effect on the norms and values of employees. Before copying "best practices" it is important to know the purpose of different courses of actions. This is especially the case with actions that affect cultural obstacles to improvement. In order to be effective "best practice" has to be "reinvented" from the organization's own situation and needs. 


\subsection{The Effect of Customer Exposure on Employee Behavior}

The identification of obstacles to improvement and leveraged actions are the breaking points of successful operations development. The interesting question is: Could there be some norms and values that are obstacles to operations development and which are common to a large number of companies?

Cultural obstacles for successful operations development are clearly evident in a study comparing employee norms and values in the Finnish metal component manufacture industry. In an extensive, in-depth study, of three machine shops employing advanced manufacturing technology Kortteinen (1992) identified fundamental obstacles to operations development in both worker and management norms and values.

The starting point of the study was to explore whether the apparent agreement of employee and management interests in the Just in Time and Lean Manufacturing concepts have had an effect on worker attitudes and actions. Kortteinen identified an "ethos of survival" as the prevailing motivator of worker behavior in the case companies. This ethos can be shortly summarized as a quest for independence and self-esteem, which in the case companies took the form of determined attempts by individual workers to "out-wit" and seize control over the manufacturing system. Even though much effort had been spent in the case plants on reshaping and streamlining the organization, and developing training and technical competence, a high barrier remained between production workers and management.

The conflict of interests between management and workers seriously constrained the opportunities of the firms for a fast and fluent customer oriented operation. Generally, line management was well aware of this situation but was not able to do much in fear of the potentially disruptive actions of production workers. In a historical perspective this is very similar to the problem Taylor (1911) set out to solve by a rational and controllable work organization.

Kortteinen (ibid.) expanded the scope of his study from the male dominated manufacturing operations to female bank clerks. The objective was to explore the determinants of worker attitudes and actions in a completely different type of industry undergoing a similar process of dramatic reorganization and operations development. The unexpected result was to find the same basic "ethos of survival" among the bank clerks. However, the energies of workers to acquire independence and self-esteem were not directed against the organization and management, but towards building a circle of loyal customers preferring the personal service of the worker.

The different behavior driven by the same basic motivation prompts us to ask: Is very strong customer exposure the leveraged action to align employee and management interests? In that case a strategy for successful operations development in manufacturing industries would be to find ways to organize so that industrial employees are able to be as proud of their own customers as bank clerks are.

The significance of being exposed to the customer or not is essential. The problems with machining workers "out-witting" the work organization in the companies studied by Kortteinen (ibid.), can be seen as a result of the absence of customers, i.e. the operation did not have true customers with a choice. The machining operations were upstream operations servicing assembly cells or finishing operations. In one of the companies studied, a very substantial reorganization of 
assembly work has recently been concluded. Assembly workers manage the whole delivery process from order processing to installation support. The lead time from order entry to delivery for standard products has been reduced from three weeks to less than one day, including manufacturing of key parts.

The basic problem can now be defined. The "ethos of survival" may be directed either towards a destructive struggle for control and independence or towards a constructive effort to build self-esteem through servicing the customer. Critical determinants for employee behavior are the position in the value adding chain and the relation to the customer. Business process redesign can affect employee behavior by increasing process visibility and removing information barriers, i.e. to diminish differences between positions in the value adding chain. Pull control, i.e. building a chain of customers (Schonberger, 1990), is effective where ever it can be applied.

However, it is not enough to improve process visibility and information flow in one direction only. Visibility of the customer in upstream operations is only part of what is required. Upstream operations also need to experience that their performance is visible to the customer. It is necessary to expose upstream operations to the customer to induce employees to build self-esteem through servicing the customer. Nevertheless, it is not desirable that the customer has to deal with a great number of persons engaged in producing the services she requires. The ideal, from the perspective of customer exposure, is that one individual or group is simultaneously responsible for the whole value adding process and all customer contacts. When this is not possible, each organization must find its model to expose employees to the customer throughout the value adding chain without overwhelming the customer with communication requests and information.

\section{Conclusions}

Distorted communication is a major cause of operational uncertainty. By reducing response times throughout the supply chain demand distortion is reduced. However, the problem of demand distortion is not restricted only to long supply chains with long lead times and poor communication. Practices inside the firm also contribute to the distortion, especially if the complexity of demand is high. By introducing planning and control practices that preserve overview and clarity the distortion can be significantly reduced.

Efforts to improve the operational performance can only be successful if people's perceptions are affected and experiences are accumulated. Customer exposure appears to be a key factor to overcome problems of diverging interests within industrial firms. Regarded from the perspective of organizational innovation customer exposure may be an equally powerful enabling factor to improvement as quantitative quality control tools and formal procedures were in the ascent of the Japanese industry.

\section{REFERENCES}

Burbidge, J. L. (1989), "Production Flow Analysis - For planning Group Technology", Clarendon Press, Oxford

Burbidge, J. L. (1994), "The use of period batch control (PBC) in the implosive industries", Production Planning \& Control, 1994, vol 5 , no 1, 97-102

Buzzell, R. D. \& Gale, B.T. ( 1987), "The PIMS Principles - Linking Strategy To Performance", The Free Press, New York 
Drucker, P. (1990), "The Emerging Theory of Manufacturing", HBR May-June 1990, pp. 94-99

Forrester, J. (1958), "Industrial Dynamics, a major breakthrough for decision makers", Harvard Business Review, July/August 1958, pp. 37-66

Holmström, J. B. (1993), "Realizing the productivity potential of expeditious operations", Licentiate's Thesis, Helsinki University of Technology

Houlihan, J. B. (1987), "International supply chain management", International Journal of Physical Distribution and Materials Management, 17 (2) 51-66

Ishikawa, K. (1985), "What is Total Quality Control? - The Japanese Way", Prentice-Hall, Englewood Cliffs, N.J.

Kortteinen, M. (1992), "Kunnian kenttä", Doctoral Thesis, Helsinki University (in Finnish)

Lillrank, P. (1988), "Organization for Continuous Improvement - Quality Control Circle Activities in Japanese Industry", Doctoral Thesis, Helsinki University

Schonberger, R. (1990), "Building a Chain of Customers", The Free Press, New York

Senge, P. (1990), "The Fifth Discipline -The Art \& Practice of The Learning Organization", Doubleday/Currency, N.Y

Taylor, F. W. (1911), "The Principles of Scientific Management", New York: W.W Norton, 1911, 1947

Towill D. R. (1992), "Supply chain dynamics - the change engineering challenge of the mid 1990s", Proc Instn Mech Engnrs Vol 206, pp 233 - 245 